\title{
Indocyanine green and poly I:C containing thermo-responsive liposomes used in immune-photothermal therapy prevent cancer growth and metastasis
}

\author{
$\mathrm{Li} \mathrm{Xu}^{1 \dagger}$, Wei Zhang ${ }^{1 \dagger}$, Hae-Bin Park ${ }^{2 \dagger}$, Minseok Kwak ${ }^{3}$, Junghwan Oh ${ }^{4,5,6}$, Peter C. W. Lee ${ }^{7}$ and Jun-O Jin ${ }^{1,2^{*}}$ (D)
}

\begin{abstract}
Background: Efficient cancer therapy is sought not only for primary tumor treatment but also for the prevention of metastatic cancer growth. Immunotherapy has been shown to prevent cancer metastasis by inducing antigenspecific immune responses. Indocyanine green (ICG) has a peak spectral absorption at about $800 \mathrm{~nm}$, which makes it a photothermal reagent for direct treatment of solid tumors by photothermal therapy (PTT). Since PTT alone cannot fully induce antigen-specific immune response for prevention of cancer metastasis, the combination of PTT and immunotherapy has been developed as a new strategy of cancer treatment.

Methods: Thermal responsive liposomes (TRL) were synthesized by incorporating ICG into the lipid bilayer and encapsulating the water-soluble immune stimulatory molecule polyinosinic:polycytidylic acid (poly I:C) in the hydrophilic core. The poly I:C- and ICG-containing TRLs (piTRLs) were analyzed according to size, and their photothermal effect was evaluated following laser irradiation at $808 \mathrm{~nm}$. Moreover, the temperature-dependent release of poly I:C was also measured. For cancer therapy, CT-26 (carcinoma) and B16 (melanoma) cells were subcutaneously inoculated to build the 1st transplanted tumor in BALB/C and C57BL/6 mice, respectively. These mice received a 2 nd transplantation with the same cancer cells by intravenous inoculation, for evaluation of the anti-metastatic effects of the liposomes after PTT.
\end{abstract}

Results: Near-infrared (NIR) laser irradiation increased the temperature of piTRLs and effectively released poly I:C from the liposomes. The increased temperature induced a photothermal effect, which promoted cancer cell apoptosis and dissolution of the 1st transplanted tumor. Moreover, the released poly I:C from the piTRL induced activation of dendritic cells (DCs) in tumor draining lymph node (tdLN). Cancer cell apoptosis and DC-activationmediated cancer antigen-specific immune responses further prevented growth of lung metastatic cancer developed following intravenous transplantation of cancer cells.

Conclusion: These results demonstrated the potential usage of a piTRL with laser irradiation for immunophotothermal therapy against various types of cancer and their metastases.

Keywords: Liposome, Indocyanine green, Polyinosinic:polycytidylic acid, Photothermal therapy, Immunotherapy, Anti-metastasis

\footnotetext{
* Correspondence: jinjo@yu.ac.kr

${ }^{\dagger}$ Li Xu, Wei Zhang and Hae-Bin Park contributed equally to this work.

'Shanghai Public Health Clinical Center \& Institutes of Biomedical Sciences,

Shanghai Medical College, Fudan University, Shanghai 201508, China

${ }^{2}$ Department of Medical Biotechnology, Yeungnam University, Gyeongsan

38541, South Korea

Full list of author information is available at the end of the article
}

(c) The Author(s). 2019 Open Access This article is distributed under the terms of the Creative Commons Attribution 4.0 International License (http://creativecommons.org/licenses/by/4.0/), which permits unrestricted use, distribution, and

reproduction in any medium, provided you give appropriate credit to the original author(s) and the source, provide a link to the Creative Commons license, and indicate if changes were made. The Creative Commons Public Domain Dedication waiver (http://creativecommons.org/publicdomain/zero/1.0/) applies to the data made available in this article, unless otherwise stated. 


\section{Background}

Photothermal therapy (PTT) has been developed as an alternative treatment strategy for tumors. This technique that uses heat-generated thermal energy to kill tumor cells by nanoparticles absorbing near-infrared (NIR) light [1-4]. PTT promotes apoptosis of cancer cells via a thermal reaction $[5,6]$ which is cleared by immune cells [7-9]. Indocyanine green (ICG) is a photothermal reagent used in medical diagnostics and photothermal therapy $[10,11]$. ICG has a peak spectral absorption at about $800 \mathrm{~nm}$, and its temperature increases upon irradiation with NIR light $[10,11]$. ICG has been approved as a NIR clinical imaging agent by the Food and Drug Administration (FDA) in the USA due to low incidence rates of adverse reactions $[12,13]$.

Since the success of immunotherapy relies on the patient's own immunity, the interest in this method of treatment of cancer has greatly increased [14]. Therapies such as monoclonal antibodies (Abs), immune cell transfer, immune checkpoint-inhibitors, and cancer vaccines have been developed and applied to the treatment of cancer [15-19]. Moreover, recent therapeutic trials have achieved effective treatments of cancer, which, however, have exhibited undesirable side effects such as inflammation [20-22]. In addition, the induction of antigen- (Ag-) specific immune responses is another therapeutic approach and prevention strategy against cancer. However, additional studies are required due to the lack of suitable candidates and the poor immune stimulatory effect of cancer Ags. Despite these immunotherapies, metastasis, which causes the majority of cancer-related deaths, is another obstacle faced by scientists in their efforts to cure cancer [23]. Therefore, to achieve the ultimate cancer therapy, not only must the primary cancer should be treated, but metastasis must also be prevented.

To enhance the efficiency of cancer therapeutics, researchers are studying a combination of therapies, since such an approach has been shown to have beneficial effects including the prevention of metastatic cancer and the reduction of side effects [20-22]. In this study, we developed a poly I:C and ICG containing temperaturesensitive liposomes (piTRLs). We hypothesized that piTRLs could treat primary tumors through the administration PTT and prevent metastatic lung cancer via immunotherapy in mice in vivo; the current study was undertaken to test this hypothesis.

\section{Material and methods}

\section{Synthesis of the temperature-sensitive liposome}

Liposomes (DPPC, MPPC, and DSPE-PEG2000 in the molar ratio of $86: 10: 4$ ) were prepared by a thin film hydration method as described in a previous study [24]. Briefly, lipids were resuspended with chloroform, and ICG was blended in methanol (ICG: lipid = 20:1 in weight ratio). The resultant solution was removed under nitrogen gas at room temperature (RT) for 1.5 $\mathrm{h}$, followed by vacuum drying for at least $4 \mathrm{~h}$. The dried lipid films were hydrated at $65^{\circ} \mathrm{C}$ with PBS or $1 \mathrm{mg} / \mathrm{ml}$ poly I:C solution in PBS for $1 \mathrm{~h}$. Then the suspension was extruded through a polycarbonate membrane of $200 \mathrm{~nm}$ using a mini-extruder (Avanti Polar Lipids, Alabaster, AL).

\section{Determination of poly I:C concentration in liposome}

The loaded concentration of poly I:C in the liposomes was determined by: isolating the fresh liposomes from the aqueous suspension medium by ultracentrifuge (20,000 rpm, $4{ }^{\circ} \mathrm{C}$ for $30 \mathrm{~min}$ ) (Optima L-100XP, Beckman, USA). The concentration of un-encapsulated poly I:C in the buffer was measured by a GeneJET RNA Cleanup and Concentration Micro Kit (Thermo fisher scientific, Waltham, MA, USA) according to the manufacturer's instructions. The concentration of poly I:C in the liposomes was calculated by the difference between total quantity and supernatant concentration of poly I:C after extrusion. The encapsulated efficiency of poly I:C in the liposomes was $18.7 \%$, which was $200 \mu \mathrm{g} / \mathrm{ml}$ of poly I:C.

\section{Characterization of liposomes}

Field emission transmission electron microscopy (FETEM) and electron diffraction (ED) pattern images were taken using a JEM-2100F transmission electron microscope (JEOL; Tokyo, Japan). UV-vis absorption spectra were recorded using a UV-visible spectrophotometer (Beckman Coulter; Fullerton, CA, USA). A fiber-coupled continuous-wave diode laser $(808 \mathrm{~nm}$, $10 \mathrm{~W})$ was purchased from Changchun New Industries Optoelectronics Technology Co., Ltd. (Changchun, China). Thermographic images and changes of temperature were taken by a FLIR ONE (FLIR Systems, Wilsonville, OR, USA).

\section{Mice and cell lines}

C57BL/6 mice and BALB/c mice were obtained from Shanghai Public Health Clinical Center and kept under pathogen-free conditions. The mice were maintained in a room with controlled temperature (20$22^{\circ} \mathrm{C}$ ), humidity (50-60\%), and light (12 h: $\left.12 \mathrm{~h}\right)$ with free access to standard rodent chow and water. Mice were euthanized by $\mathrm{CO}_{2}$ inhalation, and all efforts were made to minimize suffering. The murine melanoma cell line B16F10 (ATCC, CRL-6475) and the murine carcinoma cell line CT-26 (ATCC, CRL-2638) were cultured in RPMI 1640 (Sigma Aldrich, St. 
Louis, MO, USA) supplemented with 10\% FBS, $2 \mathrm{mM}$ glutamine, $1 \mathrm{M}$ HEPES, $100 \mu \mathrm{g} / \mathrm{ml}$ streptomycin, 100 $\mathrm{U} / \mathrm{ml}$ penicillin, and $2 \mathrm{mM} 2$-mercaptoethanol. All cell lines were cultured at $37^{\circ} \mathrm{C}$ in a humidified atmosphere of $5 \% \mathrm{CO}_{2}$ and air.

\section{Antibodies (abs)}

Mouse Abs and isotype control Abs (IgG1, IgG2a or IgG2b), CD11c (HL3), CD4 (GK1.5), CD8 $\alpha$ (YTS169.4), CD40 (3/23), CD80 (16-10A1), and CD86 (GL-1) were obtained from BioLegend (Snd Diego, CA, USA); antiMHC class I (AF6-88.5.3) and anti-MHC class II (M5/ 114.15.2) Abs were obtained from eBioscience (San Diego, CA, USA).

\section{Flow cytometry analysis}

Cells were washed with PBS containing 0.5\% BSA, pre-incubated for $15 \mathrm{~min}$ with unlabeled isotype control Abs and Fc block Abs (BioLegend, San Diego, CA, USA), and then labeled with fluorescenceconjugated Abs by incubation on ice for $30 \mathrm{~min}$ followed by washing with PBS. Cells were analyzed with FACS Fortessa (Becton Dickinson, Franklin Lakes, New Jersey, USA) and FlowJo 8.6 software (Tree Star, San Diego, CA, USA). Cellular debris were excluded from the analysis by forward- and side-scatter gating. Dead cells were further excluded by $4^{\prime}, 6-$ diamidino-2-phenylindole (DAPI) (Sigma-Aldrich) staining and gating on the DAPI-negative population. As a control for nonspecific staining, isotype-matched irrelevant mAbs were used.

\section{In vitro photothermal treatment}

CT-26 cells $\left(1 \times 10^{5}\right)$ were seeded into a 24 -well plate for $24 \mathrm{~h}$. After $1 \mathrm{~h}$ of treatment, the cells were irradiated with an $808-\mathrm{nm}$ laser at $1 \mathrm{~W} / \mathrm{cm}^{2}$ for $5 \mathrm{~min}$.

\section{MTT assay}

CT-26 cells $\left(2 \times 10^{4}\right)$ were seeded into a 96 well plate for $24 \mathrm{~h}$. Then, $100 \mu \mathrm{L}$ of freshly prepared MTT solution $(5 \mathrm{mg} / \mathrm{mL}$ in PBS) was added to each well, after which $100 \mu \mathrm{L}$ of Dimethyl sulfoxide (DMSO, Gibco; Paisley, UK) was added and incubation was initiated for an additional $4 \mathrm{~h}$. The wells were analyzed by an ELISA reader at $620 \mathrm{~nm}$ (Labsystems Multiskan; Roden, Netherlands).

\section{Apoptosis assay}

Cells were stained with annexin V-FITC and 7AAD in $100 \mu \mathrm{L}$ of binding buffer for $15 \mathrm{~min}$ at RT. The cells were analyzed by flow cytometry using a FACS Fortessa (Becton Dickinson, Franklin Lakes, New Jersey, USA) after $400 \mu \mathrm{L}$ of binding buffer was added without washing.

\section{Western blot analysis}

CT-26 cells were treated with lysis buffer containing $1 \%$ Triton X-100, $10 \%$ glycerol, $137 \mathrm{mM} \mathrm{NaCl}, 1.5$ $\mathrm{mM} \mathrm{MgCl} 2,1 \mathrm{mM}$ EGTA, and protease inhibitors. Proteins in the cell lysate were separated by $10 \%$ SDS-PAGE and transferred to nitrocellulose membranes. The membranes were incubated with a blocking buffer $(10 \mathrm{mM}$ Tris- $\mathrm{HCl}, 0.15 \mathrm{M} \mathrm{NaCl}$, $0.1 \% \mathrm{NaN}_{3}$, and $5 \%$ skim milk) for $1 \mathrm{~h}$ and stained with anti-procaspase-3, -8 and -9 Abs overnight at $4{ }^{\circ} \mathrm{C}$. The membranes were stained with the secondary $\mathrm{Abs}$ for $2 \mathrm{~h}$, and signals were detected using ECL chemiluminescence following the manufacturer's instructions.

\section{Mouse DC analysis}

Tumor-draining lymph node (tdLN) DCs were analyzed as described in other studies [25, 26]. Briefly, the tdLN were homogenized and digested with collagenase for $20 \mathrm{~min}$ at room temperature (RT). Cells were centrifuged into a pellet and resuspended in 5 $\mathrm{mL}$ of histopaque-1.077 (Sigma-Aldrich, St. Louis, MO, USA). Additional histopaque-1.077 was layered below, and $1 \mathrm{ml}$ of FBS was layered above the cell suspension. The tube was centrifuged at $1700 \mathrm{x}$ g for 10 min without break. The light density fraction (< $1.077 \mathrm{~g} / \mathrm{cm}^{3}$ ) was harvested and stained with the following FITC-conjugated monoclonal Abs (mAbs) for 30 min: anti-CD3 (17A2), anti-Thy1.1 (OX-7), antiB220 (RA3-6B2), anti-Gr1 (RB68C5), anti-CD49b (DX5), and anti-TER-119 (TER-119). The lineage $^{-} \mathrm{CD} 11 \mathrm{c}^{+}$cells were defined as DCs, which were further divided into $\mathrm{CD} 8 \alpha^{+}$and $\mathrm{CD} 8 \alpha^{-}$DCs. Analysis was carried out on a FACS Fortessa (Becton Dickinson, Franklin Lakes, NJ, USA).

\section{Real-time PCR}

Total RNA was reverse-transcribed into cDNA using Oligo (dT) and M-MLV reverse transcriptase (Promega, Madison, Wisconsin, US). The cDNA was subjected to real-time PCR amplification (Qiagen, Hilden, Germany) for 40 cycles with annealing and extension temperature at $60^{\circ} \mathrm{C}$ on a LightCycler 480 Real-Time PCR System (Roche, Basel, Switzerland). Primer sequences were: mouse $\beta$-actin forward, 5'-TGGATG ACGATATCGCTGCG-3'; reverse, 5'-AGGGTCAG GATACCTCTCTT-3', IL-6 forward, 5'-AACGATGA TGCACTTGCAGA-3'; reverse, 5'-GAGCATTGGA AATTGGGGTA-3', IL-12p40 forward, 5'-CACATC TGCTGCTCCACAAG-3'; reverse, 5' - CCGTCCGG AGTAATTTGGTG-3', TNF- $\alpha$ forward, $5{ }^{\prime}$-CCTTTC ACTCACTGGCCCAA-3'; reverse, 5'-AGTGCCTCTT CTGCCAGTTC-3' T-bet forward, 5' -CAACAACCCC TTTGCCAAAG-3'; reverse, 5'-TCCCCCAAGCATTG 
ACAGT-3', GATA3 forward, 5'-CGGGTTCGGATG TAAGTCGAGG-3'; reverse, 5' - GATGTCCCTGCT CTCCTTGCTG-3', RORyt forward, 5'-CCGCTGAG AGGGCTTCAC-3'; reverse 5'-TGCAGGAGTAGGCC ACATTACA-3', IFN- $\gamma$ forward, 5'-GGATGCATTC ATGAGTATTGC-3'; reverse, 5' -CTTTTCCGCTTC CTGAGG-3', IL-4 forward, 5'-ACAGGAGAAGGGAC GCCAT-3'; reverse 5'-GAAGCCCTACAGACGAGC TCA-3', IL-17A forward, 5'-GCGCAAAAGTGAGC TCCAGA-3'; reverse 5' -ACAGAGGGATATCTATCA GGG-3'.

\section{In vivo photothermal treatment}

Once tumors at their longest dimension reached a size of approximately $5.0 \mathrm{~mm}$ on day 7 , mice were randomized into eight treatment groups: PBS, TRL, iTRL, and piTRL with or without laser irradiation. Each of the liposomes was intratumorally (i.t.) injected into the mice. One hour after injection an $808 \mathrm{~nm}$ NIR laser was applied to irradiate tumors under a power intensity of $1 \mathrm{~W} / \mathrm{cm}^{2}$ for $5 \mathrm{~min}$. The temperature was recorded using an infrared camera FLR One Thermal imaging system (FLIR, Wilsonwille, OR, USA). Tumor volume was calculated by using the formula $V \frac{1}{1 / 4} 1 / 2(\mathrm{~L} / \mathrm{S} 2)$, where $\mathrm{L}$ is the longest dimension and $\mathrm{S}$ is the shortest dimension.

\section{2nd transplanted model}

$\mathrm{BALB} / \mathrm{c}$ and C57BL/6 mice were intravenously (i.v.) injected with CT-26 and B16 cells, respectively. The survival of mice was monitored for 21 days after cancer cell injection.

\section{Hematoxylin and eosin staining}

As described in detail in a previous study [27], colon, kidney, and liver samples were fixed in $4 \%$ paraformaldehyde, embedded in paraffin, and sectioned to $6 \mu \mathrm{m}$ thickness. Sections were then stained with hematoxylin and eosin $(H \& E)$ and examined for inflammation and tissue damage.

\section{ELISPOT assay}

ELISPOTs for mouse IFN- $\gamma$ were performed according to the manufacturer's protocol (Biolegend, San Diego, CA, USA). In short, IFN- $\gamma$ capture Abs were pre-coated on the plate and splenocytes were seeded at $50 \times 10^{3}$ cells/well. Fresh $2 \times 10^{6}$ CT-26 or B16 cells were lysed by freeze and thaw, respectively. After centrifugation, suspended cancer Ag proteins were harvested, and $10 \mu \mathrm{g} / \mathrm{mL}$ proteins were incubated with splenocytes at $37^{\circ} \mathrm{C}$ for $24 \mathrm{~h}$. ELISPOT plates were counted automatically using a CTL ELISPOT reader (CTL Europe GmbH, Bonn, Germany).

\section{Antigen-specific lysis of splenocytes}

A mixture of splenocytes labeled with CFSE $(200 \mathrm{nM})$ and loaded with $1 \mu \mathrm{g} / \mathrm{mL}$ cancer Ag proteins, and spleen cells labeled with $10 \mathrm{mM}$ CellTracker ${ }^{\mathrm{Tm}}$ Orange CMTMR (Life technologies) and not loaded with protein was transferred into C57BL/6 mice. Six hours after transfer, the spleen was harvested and the population of splenocytes were analyzed by Novocyte flow cytometer and NovoExpress ${ }^{\circ}$ software from ACEA Biosciences Inc. (San Diego, CA, USA).

\section{T cell depletion and blocking of co-stimulator}

Anti-CD4 (GK1.5), anti-CD8 (YTS169.4), anti-CD80 (1G10) and anti-CD86 (GL-1) Abs were intraperitoneally (i.p.) administered in the mice on day 25 after the 1 st subcutaneous inoculation of cancer cells ( 3 days before the 2nd intravenous administration of cancer cells). The Abs were purchased from BioXcells (West Lebanon, $\mathrm{NH}, \mathrm{USA}$ ) and $100 \mu \mathrm{l}$ of $1 \mathrm{mg} / \mathrm{ml} \mathrm{Abs}$ was administered every 3 days in the mice. The depletion of cells was confirmed using Novocyte flow cytometer (San Diego, CA, USA).

\section{Statistical analysis}

Results are expressed as the mean \pm standard error of the mean (SEM). Data sets were analyzed by one-way ANOVA using the Tukey multiple comparison test with GraphPad Prism 4. $P$ values smaller than 0.05 were considered to be statistically significant.

\section{Results}

piTRL induced elevated temperatures and released poly I:C in response to near-infrared (NIR) light

Using the thin-film rehydration method, TRLs (DPPC, MPPC, and DSPE-PEG2000 in a molar ratio of 86:10:4) with incorporated ICG in the lipid bilayer (iTRL) were prepared. The soluble poly I:C was then encapsulated by extrusion through a $200 \mathrm{~nm}$ size of polycarbonate membrane using a mini-extruder (piTRL). As shown in Fig. 1a, the liposomes were successfully synthesized, and all liposomes had similar size (Fig. 1b). Since the liposomes had incorporated ICG, we measured the absorption spectra of the liposomes. Both iTRLs and piTRLs have strong peak absorption rates at 811 and $791 \mathrm{~nm}$, respectively (Fig. 1c). For evaluation of the photothermal efficiency of piTRLs, we measured the changes in temperature under laser irradiation $\left(1 \mathrm{~W} / \mathrm{cm}^{2}\right)$ at 808 $\mathrm{nm}$ for $5 \mathrm{~min}$ and found that the piTRLs showed greater temperature increases in a dose-dependent manner when compared to phosphate-buffered saline (PBS). The temperatures of the 2 and $5 \mathrm{mg} / \mathrm{mL}$ piTRLs reached up to $50{ }^{\circ} \mathrm{C}$ and $58^{\circ} \mathrm{C}$, respectively, within $5 \mathrm{~min}$, whereas the temperature of PBS increased up to $28^{\circ} \mathrm{C}$ (Fig. 1d). 


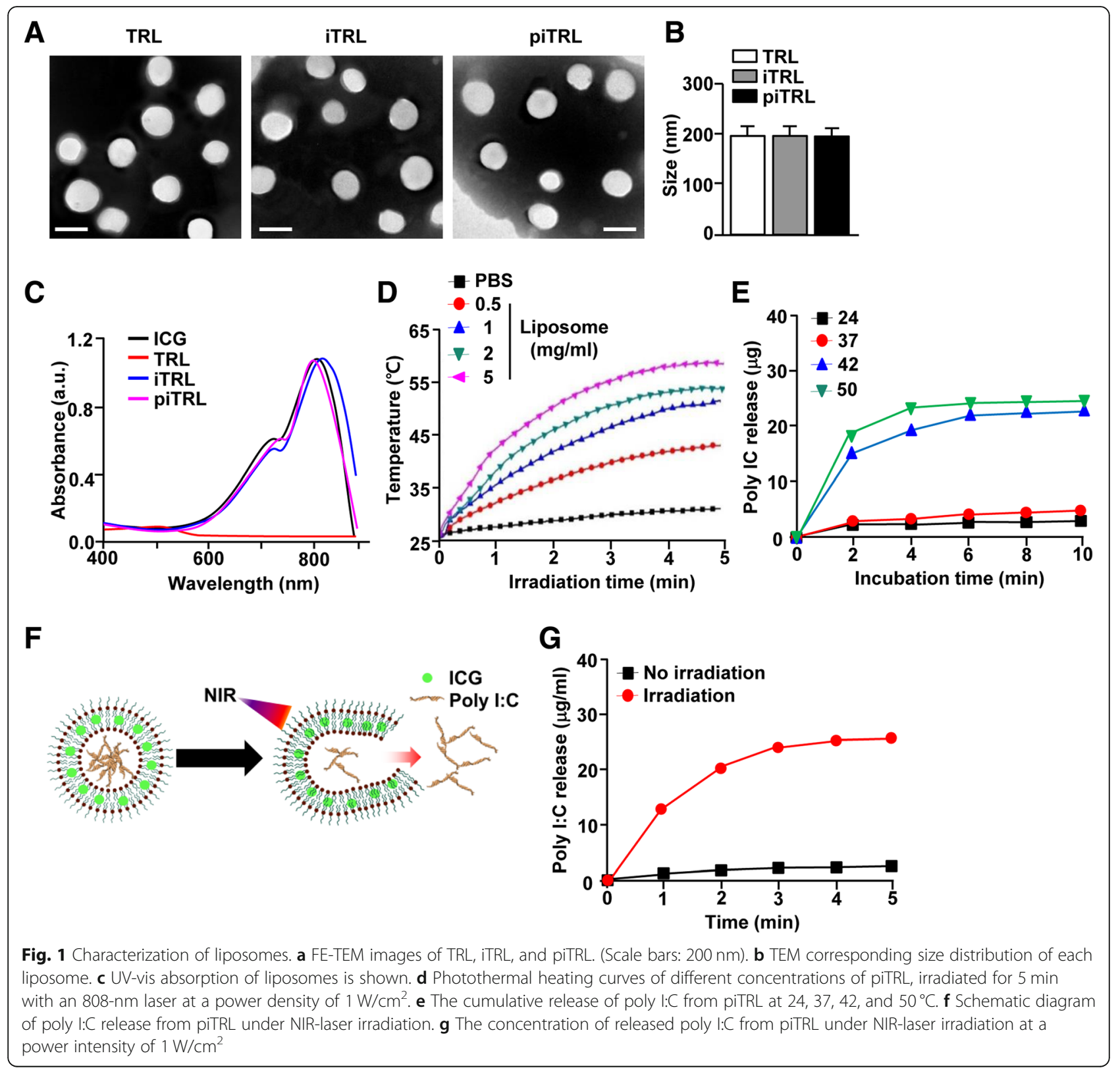

Since TRL is sensitive to high temperatures, we evaluated the release of poly I:C at different temperatures. Incubation of piTRLs at $24,37,42$ and $50{ }^{\circ} \mathrm{C}$ for $5 \mathrm{~min}$ resulted substantial release of poly I:C from the liposomes at 42 and $50{ }^{\circ} \mathrm{C}$ (Fig. 1e). Moreover, laser irradiation also induced efficient release of poly $\mathrm{I}: \mathrm{C}$ in the piTRLs within $5 \mathrm{~min}$ (Fig. If and g). Thus, these results indicated that piTRLs release poly $\mathrm{I}: \mathrm{C}$ and produce a photothermal effect.

piTRL and laser irradiation induced apoptosis of cancer cell by photothermal effect

Because laser irradiation increases the temperature of piTRLs, we next examined PTT efficiency against B16 melanoma and CT-26 carcinoma cells. Before evaluation of the photothermal effect, we studied the toxicity of the liposomes in the Raw 264.7 cells and found that the treatment with liposomes did not have any toxic effect on the cells (Additional file 1: Figure S1). Moreover, treatment of CT-26 cells with liposomes did not induce cell death in the absence of laser irradiation whereas the viability of CT-26 cells was significantly decreased following laser irradiation of iTRL- and piTRL-treated cells (Fig. 2a). Laser irradiation and treatment with iTRLs and piTRLs induced apoptotic cell death as indicated by the increases in the number of annexin- $V$-positive and 7AAD-positive cells, whereas laser irradiation and TRL treatment did not induce apoptosis of CT-26 cells (Fig. 

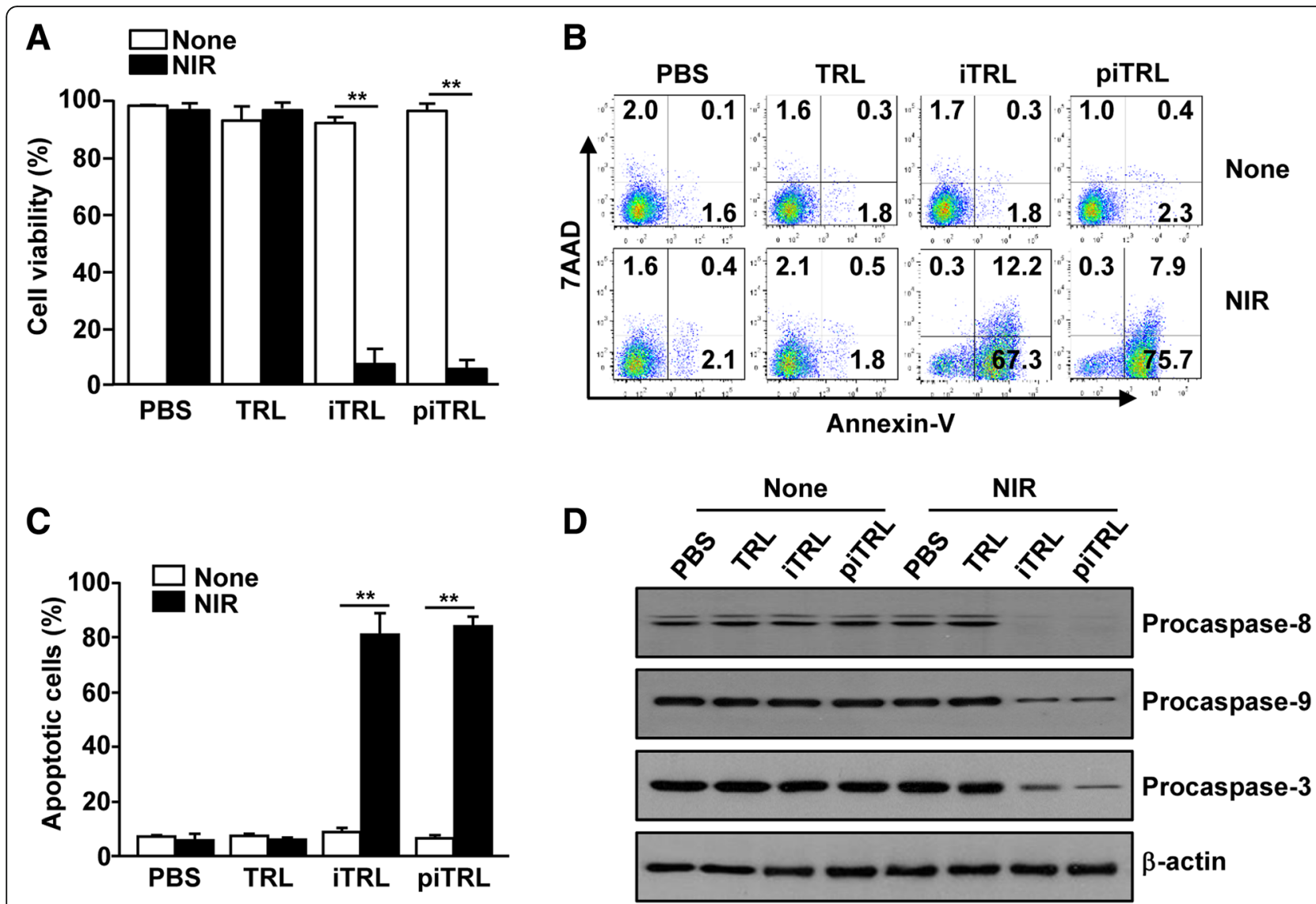

Fig. 2 piTRL and laser irradiation promoted apoptosis of CT-26 carcinoma. CT-26 cells were incubated with PBS, TRL, iTRL or piTRL for 1 h, and the cells were treated with or without laser irradiation at $1 \mathrm{~W} / \mathrm{cm}^{2}$ for $5 \mathrm{~min}$ and cultured for $24 \mathrm{~h}$. a Cell viability of CT-26 was measured by MTT assay; ${ }^{* *} p<0.01$. b Apoptosis was analyzed by annexin-V and 7AAD staining on flow cytometry. c Mean percentages of apoptotic cells, ${ }^{* *} p<$ 0.01. d The expression levels of procaspase-8, - 9, and -3 were assayed by western blotting analysis. $\beta$-actin was used as a loading control

$2 \mathrm{~b}$ and $\mathrm{c}$ ). In addition, treatment with iTRLs and piTRLs and laser irradiation resulted in the activation of apoptotic signaling pathway, since the levels of procaspase-3, -8 , and -9 , were dramatically decreased (Fig. 2d). Therefore, these results indicated that piTRL and iTRL can be used as photothermal molecules.

\section{piTRL and laser irradiation eliminated melanoma and carcinoma by photothermal therapy (PTT)}

Since the liposomes could induce cancer cell apoptosis, we next examined whether they can be used in the treatment of tumors in mice. For the evaluation of the antitumor effect of the liposomes, we assessed CT-26 carcinoma in BALB/C mice and B16 melanoma in C57BL/6 mice. Once the tumors were established on day 7 after initial implantation of tumors, we i.t. administrated the liposomes in the mice and irradiated them with an 808 $\mathrm{nm}$ laser at $1 \mathrm{~W} / \mathrm{cm}^{2}$ for $5 \mathrm{~min}$. Laser irradiation of the iTRL- and piTRL-treated tumors increased their temperatures to $52.5 \pm 1.4{ }^{\circ} \mathrm{C}$ and $53.1^{\circ} \mathrm{C} \pm 1.8^{\circ} \mathrm{C}$, respectively, whereas it did not change the temperatures of PBS- and
TRL-treated tumors (Additional file 1: Figure S2). Moreover, the tumors in BALB/c and C57BL/6 almost disappeared on day 21 after tumor injection by treatment with iTRLs and piTRLs and laser irradiation (Fig. 3a). In addition, the tumor growth also efficiently inhibited in $\mathrm{BALB} / \mathrm{c}$ and $\mathrm{C} 57 \mathrm{BL} / 6$ mice after treatment with iTRL and piTRL and laser irradiation (Fig. $3 \mathrm{~b}$ and c). Thus, these data suggested that laser irradiation of iTRL- or piTRL-treated tumors promotes PTT-mediated anticancer effects in cases of carcinoma and melanoma.

piTRL treatment with laser irradiation promoted dendritic cell (DC) activation in the tumor draining lymph node $(\operatorname{tdLN})$

Next, we evaluated the effect of piTRL-released poly I:C on lymph node (LN) dendritic cell (DC) activation. We i.t. injected liposomes in the CT-26 tumorbearing $\mathrm{BALB} / \mathrm{c}$ mice and irradiated them with an $808 \mathrm{~nm}$ laser at $1 \mathrm{~W} / \mathrm{cm}^{2}$ for $5 \mathrm{~min}$. Twenty-four hours after laser irradiation, tumor-draining LNs (tdLN) were harvested and analyzed for DC 

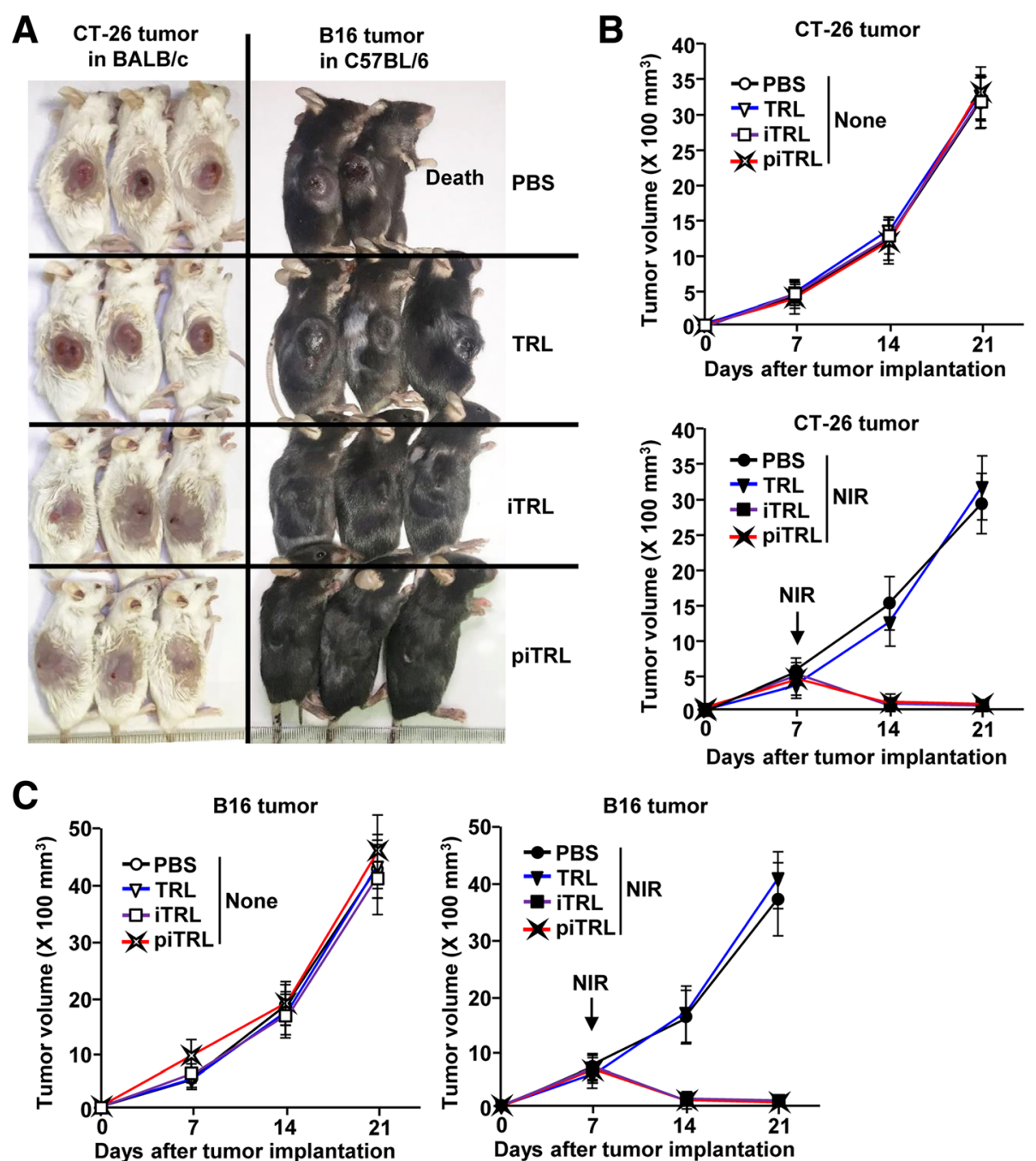

Fig. 3 Anti-cancer effect of piTRL treatment followed by laser irradiation against CT-26 carcinoma and B16 melanoma. BALB/C and C57BL/6 mice were subcutaneously (s.c.) inoculated with $1 \times 10^{6} \mathrm{CT}-26$ and B16 cells, respectively. The mice were intratumorally (i.t.) injected with PBS, TRL, iTRL, or piTRL on day 7 of tumor cell injection and were treated with or without laser irradiation at a power density of $1 \mathrm{~W} / \mathrm{cm}^{2}$ for $5 \mathrm{~min}$. a CT-26 (left panel) and B16 (right panel) tumor mass is shown on day 21 of tumor injection. b Tumor growth curves for CT-26 carcinoma with or without laser irradiation. c B16 melanoma tumor growth curves for the mice in the presence or absence of laser irradiation. Data are from the analyses of six individual mice (three mice per experiment for a total of two independent experiments)

activation. The tdLN DCs were defined as lineage $^{-} \mathrm{CD} 11 \mathrm{c}^{+}$cells in live leukocytes, and the DCs were further divided into $\mathrm{CD} 8 \alpha^{+}$and $\mathrm{CD} 8 \alpha^{-} \mathrm{DCs}$ from the lineage ${ }^{-} \mathrm{CD} 11 \mathrm{c}^{+}$cells (Fig. 4a). The mice treated with PBS, TRL, or iTRL in the presence or absence of laser irradiation did not show a change in the population and number of tdLN DCs. In contrast, treatment with piTRLs and laser irradiation promoted substantial increases in the frequency and number of DCs in tdLNs, the levels of which were almost similar to those obtained following treatment of mice with $20 \mu \mathrm{g}$ of poly I:C (Fig. 4b and c). In addition, piTRL treatment and laser irradiation induced dramatic increases in the levels of co-stimulatory molecules and the expression of major histocompatibility complex (MHC) class I and II in tdNL $\mathrm{CD} 8 \alpha^{+}$and $\mathrm{CD} 8 \alpha^{-}$ DCs (Fig. 4d). Furthermore, the mRNA levels of proinflammatory cytokines, interleukin-6 (IL-6), IL-12p40 and tumor necrosis factor- $\alpha$ (TNF- $\alpha$ ) in the tdNL were also significantly increased by treatment with piTRL and laser irradiation compared to those in controls (Fig. 4e). In addition, the mRNA levels of interferon- $\gamma$ (IFN- $\gamma)$ and T-bet, a transcription factor of Th1 cells, were also up-regulated by the piTRL treatment and laser irradiation, whereas the levels of Th2- and Th17-associated mRNA, GATA3, and RORyt were not changed (Additional file 1: Figure S3). Thus, these results suggested that poly I:C 


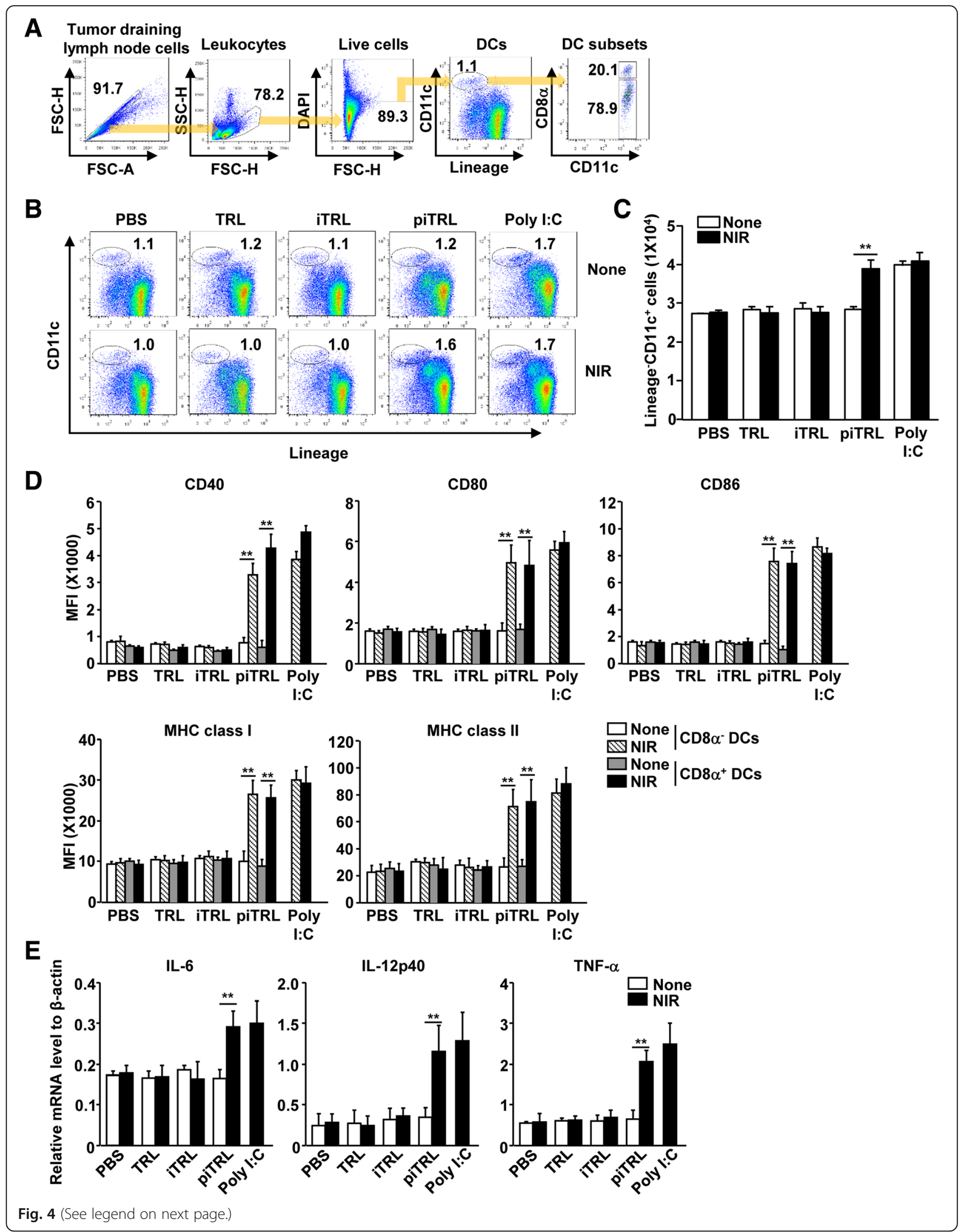


(See figure on previous page.)

Fig. 4 piTRL treatment followed by laser irradiation promoted activation in tumor-draining lymph node (tdLN). CT-26 tumor-bearing mice were i.t. injected with PBS, TRL, iTRL, piTRL or poly I:C, and treated with or without laser irradiation for $5 \mathrm{~min}$. tdLN were harvested $24 \mathrm{~h}$ after laser irradiation. a Definition of DC population in tdLN was shown. Lineage markers included CD3, Thy1.1, B220, Gr-1, CD49b, and TER-119.

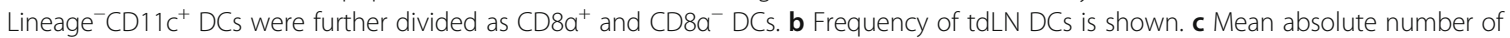
Lineage ${ }^{-} \mathrm{CD} 11 c^{+}$cells in tdLN is shown, ${ }^{* *} p<0.01$. d Mean fluorescence intensity (MFI) of co-stimulatory molecules and MHC class I and II in gated $C D 8 a^{+}$and $C D 8 a^{-}$DCs in tdLN was analyzed using flow cytometry. e Levels of IL-6, IL-12p40 and TNF-a mRNA in tdLN. All data are representative of the average of the analyses of six independent samples (i.e., three samples per experiment, two independent experiments)

released from piTRLs upon laser irradiation induced activation of DCs in the mice in vivo.

\section{Laser irradiation in piTRL-treated mice prevented metastatic cancer in lung}

Our data showing that piTRL treatment with laser irradiation was effective therapy against the growth of the 1st transplanted tumor and induced DC activation in tdLN motivated us to examine the anti-metastatic effect of piTRLs. On day 28 of 1st tumor injection, the BALB/ c and C57BL/6 mice were cured by iTRL and piTRL treatment and laser irradiation and i.v. injected with $0.5 \times 10^{6}$ CT- 26 or B16 cells for establishing metastatic models as 2nd transplantation of tumors, respectively. PBS and TRL treatment with laser irradiation did not inhibit the growth of the 1st transplanted tumors, and these mice consequently dyed within 28 days of 1 st tumor transplantation (Fig. 5a, b). The mice cured of the 1st transplanted tumors by piTRL treatment with laser irradiation survived from the 2nd i.v. tumor cell challenge during monitoring, whereas the mice cured by iTRL-mediated treatment died within 18 days of 2nd injection of cancer cells (Fig. 5a, b and Additional file 1: Figure S4). Moreover, cancer cell infiltration in the lung was substantially inhibited in mice treated with piTRL and laser irradiation compared to control mice treated with PBS, poly I:C, or iTRLs (Fig. $5 \mathrm{c}$ and d). The mice cured from the CT-26 tumor by treatment with piTRLmediated PTT were not been protected against the 2nd challenge with $4 \mathrm{~T} 1$ breast cancer cells (Additional file 1: Figure S4B), indicating that the protective effect of piTRL against the 2nd transplanted cancer depends on the 1st transplanted tumor.

Next, we evaluated whether the rejection of the 2nd transplanted cancer depended on self Ag-specific immune responses. On day 35 after $1^{\text {st }}$ tumor injection, which was day 7 of the 2nd tumor administration, spleen was harvested and splenocytes were incubated with the self-Ag of CT-26 or B16, respectively, for $24 \mathrm{~h}$. The mice treated with piTRL and laser irradiation showed significant increases in IFN- $\gamma$ production in response to selfAgs, whereas other control treated mice did not show production of IFN- $\gamma$ (Fig. 6a and b). The mice survived from the 1st transplanted tumor due to piTRL treatment showed significantly higher specific lysis of tumor Ag- coated splenocytes than iTRL and poly I:C treated mice whose splenocytes were not killed (Fig. $6 \mathrm{c}$ and d). Moreover, lung infiltrated $\mathrm{T}$ cells in piTRL-treated mice that were cured from the 1st transplanted tumor produced much higher amounts of IFN- $\gamma$ and TNF- $\alpha$ in response to cancer Ag (Additional file 1: Figure S5). In addition, depletion of CD4 and CD8 $\mathrm{T}$ cells by $\mathrm{Ab}$ treatment in piTRL-treated mice that were cured from the 1st transplanted tumor failed to protect from the 2nd transplanted cancer (Fig. 6e). Blockade of co-stimulatory molecules in mice cured from 1st transplanted tumor by piTRL also failed to protect against the 2nd transplanted cancer (Fig. 6f). Thus, these results demonstrate that the protective effect of piTRL against the 2nd transplanted cancer depends on cancer Ag-specific immune responses. Immune cell infiltration in the peripheral tissues such as the colon, kidneys, and liver was not detected in cases of piTRL treatment with laser irradiation, which indicated that piTRL with laser irradiation did not promote inflammation in peripheral tissue (Additional file 1: Figure S6). Therefore, these data suggested that the treatment of piTRL with laser irradiation cured both the 1st transplanted cancer and the 2nd transplanted cancer.

\section{Discussion}

Since liposomes have low cytotoxicity in both animals and humans, they have been extensively studied as delivery vehicles for anti-cancer drugs. The sensitivity of liposomes to temperature is an especially attractive feature since they can release encapsulated molecules in the space around the physiological temperature. Upon NIR laser-mediated increase in temperature to $42^{\circ} \mathrm{C}$, the membrane of TRLs becomes permeable, such that the encapsulated molecules are released [24, 28]. TRLs have been used with PTT and anti-cancer drug-induced chemotherapy for cancer [24]. In this study, we used a TRL system in which ICG was incorporated in the bilayer and poly I:C was encapsulated. The ICG efficiently reacted to NIR laser irradiation by increasing the temperature and effectively releasing poly I:C. Therefore, the piTRLs may be used for PTT and immunotherapy against cancer and its metastasis. 


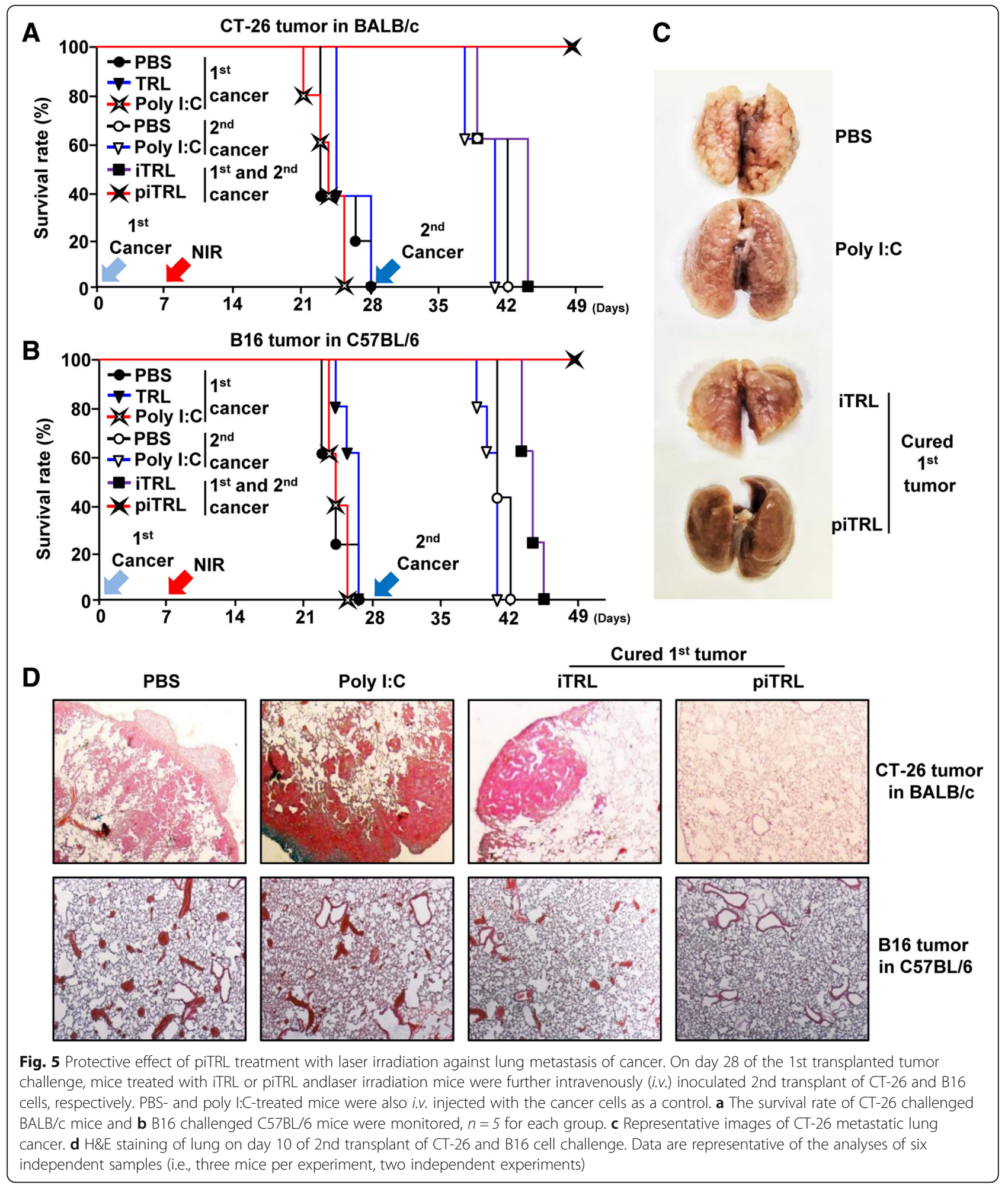

Immunotherapy aims to promote Ag-specific immune responses against cancer Ags that lead to efficient and selective killing of cancer cells $[29,30]$. Ag-specific immune responses are controlled by Ag presenting cells such as DCs, macrophages, and B cells [29, 30]. Among these, DCs are the most potent Ag presenting cells [31]. In mice, myeloid types of DCs contained two main subsets: $\mathrm{CD} 8 \alpha^{+}$and $\mathrm{CD} 8 \alpha^{-}$DCs. The $\mathrm{CD} 8 \alpha^{+}$DCs are 


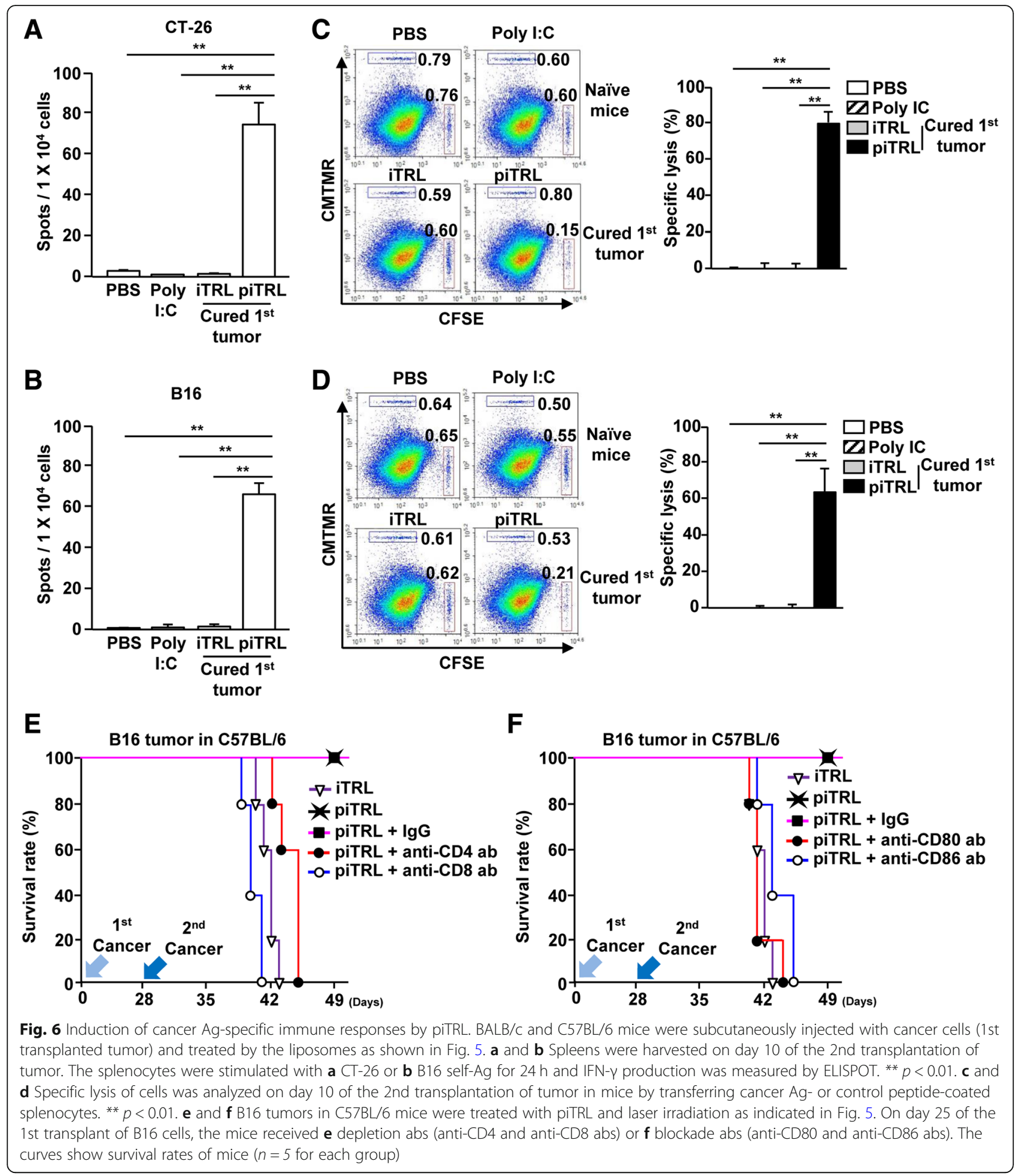

specialized in the cross-presentation of $\mathrm{Ag}$ to $\mathrm{CD}^{+} \mathrm{T}$ cells, which are primed for cytotoxic $\mathrm{T}$ lymphocyte (CTL) response. On the other hand, $\mathrm{CD} 8 \alpha^{-}$DCs present exogenous $\mathrm{Ag}$ to $\mathrm{CD}_{4}^{+} \mathrm{T}$ cells, then developing into helper $\mathrm{T}(\mathrm{Th})$ cells for the production of cytokines
[32-34]. These subsets of DC activation are essential for Ag-specific immunotherapy against cancer. We found that piTRL treatment with laser irradiation induced both $\mathrm{CD} 8 \alpha^{+}$and $\mathrm{CD} 8 \alpha^{-}$DC activation. Taken together with the PTT-induced apoptosis of tumor cells, the 
stimulatory effect of piTRLs in tdLN DCs may promote Ag-specific immune responses for protection against cancer metastasis.

It has been found that PTT induces cancer cell apoptosis [6, 35]. Apoptosis is programmed cell death, and cancer Ags are generated by the apoptosis of cancer cells [7]. Although many studies have attempted to induce the apoptosis of cancer cells, the cancer cell apoptosisgenerated molecules do not completely prevent metastasis because the cancer Ags are poorly immunogenic $[23,36]$. While the iTRL treatment with laser irradiation successfully cured the $1^{\text {st }}$ transplanted tumors in our study, it could not inhibit growth of the 2nd transplanted cancer growth in BALB/c and C57BL/6 mice. This failure of iTRL to provide protection against the2nd transplanted cancer may be due to less immune activation by apoptosis-generated molecules [36-39], as we have shown that iTRL treatment with laser irradiation did not promote DC activation in tdLNs and specific killing of cancer Ag-coated splenocytes. In contrast, piTRL-designed to release poly I:C upon laser irradiation induced activation of tdLN DCs. Moreover, PTTinduced apoptosis of tumor cells produces tumor Ags, and the released poly I:C may promote tumor Ag-specific immune activation. This consequently may have prevented growth of the $2^{\text {nd }}$ transplanted cancer in mice cured of the 1st transplanted tumors. Moreover, depletion of $\mathrm{T}$ cells and blockade of co-stimulatory molecules failed to protect mice from the 2nd transplanted cancer. Taken together, these results demonstrated that the piTRL-induced protective effect against the 2nd transplanted cancer was mediated by DC and $\mathrm{T}$ cell activation. We also found that within $24 \mathrm{~h}, 40 \%$ of the encapsulated poly I:C was released from piTRL without laser irradiation at $30^{\circ} \mathrm{C}$; however, it did not induce activation of DCs in the tdLN. This may be due to two reasons. First, immune stimulatory amount of poly I:C is $20 \mu \mathrm{g}$ in the mouse in vivo, but the amount of the poly I: $\mathrm{C}$ spontaneously released from the liposomes was $8 \mu \mathrm{g}$, which may not be enough to induce DC activation. Second, the spontaneous release of poly I:C may be very slow, which may promote immune tolerance against poly I:C. To evaluate the effect of the slow release of poly I:C on DC activation, we plan to synthesize poly I: C-containing hydrogel and examine the effect of DC activation in the mice in vivo.

\section{Conclusions}

To develop novel therapeutic materials for combination therapy against cancer, nanoscience can be of great help $[40,41]$. Since nanocarriers can carry appropriate molecules, it would be beneficial to combine new therapeutic molecule for delivery of those molecules to tumor for more complex trials [40-44]. As shown in Fig. 7, we developed a TRL containing a photothermal reagent, ICG, and an immune stimulatory molecule, poly I:C, which suitably increased temperatures against NIR laser irradiation for inducing PTT and releasing poly I:C for the promotion of immune activation. This combination eventually showed some success against subcutaneous tumors in a mouse model and against metastatic growth of carcinoma and melanoma in BALB/c and C57BL/6 mice via cancer Ag-specific immune activation. Thus, piTRL is a promising candidate for the treatment of cancer and prevention of metastasis as a photothermal and immunotherapy material.

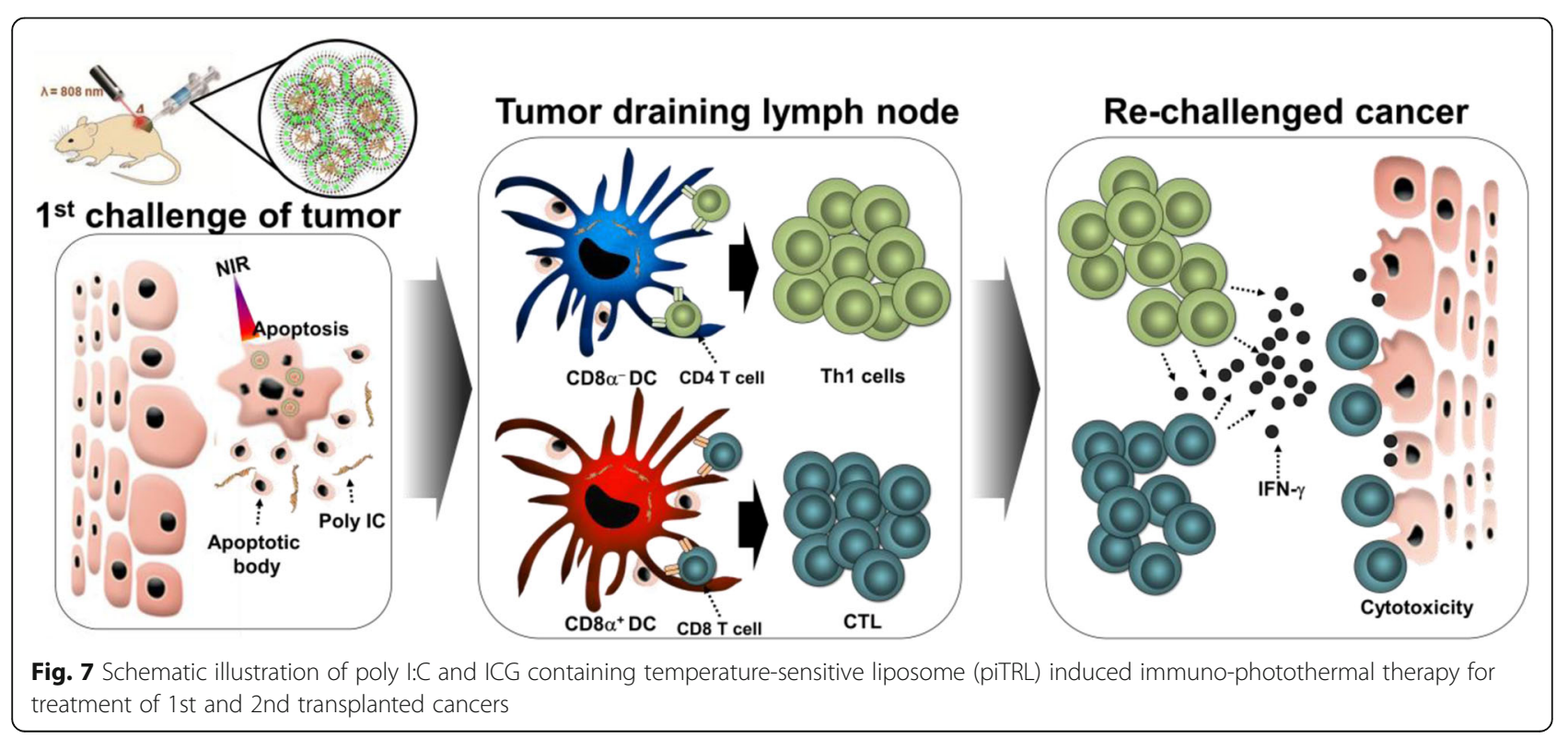




\section{Additional file}

Additional file 1: Figure S1. Cell viability upon liposome treatment. Figure S2. Changes in temperature in liposome-treated tumor by NIR laser irradiation. Figure S3. piTRL treatment and laser irradiation promoted IFN- $\gamma$ production. Figure S4. Survival rate of CT-26 and B16challenged BALB/C and C57BL/6 mice. Figure S5. Cancer antigen-specific IFN- $\gamma$ and TNF-a production. Figure S6. Hematoxylin and eosin (H\&E) staining of peripheral tissues. (DOCX $771 \mathrm{~kb}$ )

\section{Abbreviations}

Ag: Antigen; CTL: Cytotoxic T lymphocyte; DC: Dendritic cell; ED: Electron diffraction; FE-TEM: Field emission transmission electron microscopy; ICG: Indocyanine green; IFN: Interferon; IL: Interleukin; LN: Lymph node; MHC: Major histocompatibility complex; NIR: Near-infrared; Poly I:C: Polyinosinic:polycytidylic acid; PTT: Photothermal therapy; Th: Helper T; TNF: Tumor necrosis factor; TRL: Thermo-responsive liposome

\section{Acknowledgments}

We thank the Shanghai Public Health Clinical Center and Yeungnam University animal facility for maintaining the animals in this study.

\section{Authors' contributions}

LX: designed, analyzed and interpreted data. WZ: designed, conducted, and analyzed data. HP: conducted and analyzed data. MK: designed and interpreted data. JO: designed and interpreted data. PCL: designed, conducted, analyzed and interpreted data. JOJ: designed, conducted, analyzed and interpreted data, conceived and supervised project, edited manuscript. All authors read and approved the final manuscript.

\section{Funding}

National Research Foundation of Korea (NRF-2019R1C1C1003334);

National Natural Science Foundation of China (81874164)

\section{Availability of data and materials}

The data supporting the conclusions of this article are displayed within the article and additional files. The actual raw data are available from the corresponding author on reasonable request.

\section{Ethics approval and consent to participate}

All experiments were carried out under the guidelines of the Institutional Animal Care and Use Committee at the Shanghai Public Health Clinical Center. The protocol was approved by the Committee on the Ethics of Animal Experiments of the Shanghai Public Health Clinical Center (Mouse Protocol Number: 2018-A015-01) and the Yeungnam University (2019-009).

\section{Consent for publication}

Not applicable

\section{Competing interests}

The authors declare that they have no competing interests.

\footnotetext{
Author details

${ }^{1}$ Shanghai Public Health Clinical Center \& Institutes of Biomedical Sciences, Shanghai Medical College, Fudan University, Shanghai 201508, China. ${ }^{2}$ Department of Medical Biotechnology, Yeungnam University, Gyeongsan 38541, South Korea. ${ }^{3}$ Department of Chemistry, Pukyong National University, Busan 48513, South Korea. ${ }^{4}$ Marine-Integrated Bionics Research Center, Pukyong National University, Busan 48513, South Korea. ${ }^{5}$ Department of Biomedical Engineering and Center for Marine-Integrated Biomedical Technology (BK21 Plus), Pukyong National University, Busan 48513, South Korea. ${ }^{6}$ Interdisciplinary Program of Biomedical Mechanical \& Electrical Engineering, Pukyong National University, Busan 48513, South Korea. ${ }^{7}$ Department of Biomedical Sciences, University of Ulsan College of Medicine, ASAN Medical Center, Seoul, South Korea.
}

Received: 14 February 2019 Accepted: 31 July 2019

Published online: 14 August 2019

\section{References}

1. Ban Q, Bai T, Duan X, Kong J. Noninvasive photothermal cancer therapy nanoplatforms via integrating nanomaterials and functional polymers. Biomater Sci. 2017;5(2):190-210.

2. Shanmugam V, Selvakumar S, Yeh CS. Near-infrared light-responsive nanomaterials in cancer therapeutics. Chem Soc Rev. 2014;43(17):6254-87.

3. Jang B, Moorthy MS, Manivasagan P, Xu L, Song K, Lee KD, Kwak M, Oh J, Jin JO. Fucoidan-coated CUS nanoparticles for chemo-and photothermal therapy against cancer. Oncotarget. 2018;9(16):12649-61.

4. Jang B, Xu L, Moorthy MS, Zhang W, Zeng L, Kang M, Kwak M, Oh J, Jin JO. Lipopolysaccharide-coated CUS nanoparticles promoted anti-cancer and anti-metastatic effect by immuno-photothermal therapy. Oncotarget. 2017; 8(62):105584-95.

5. Mkandawire MM, Lakatos M, Springer A, Clemens A, Appelhans D, KrauseBuchholz U, Pompe W, Rodel G, Mkandawire M. Induction of apoptosis in human cancer cells by targeting mitochondria with gold nanoparticles. Nanoscale. 2015;7(24):10634-40.

6. Perez-Hernandez M, Del Pino P, Mitchell SG, Moros M, Stepien G, Pelaz B, Parak WJ, Galvez EM, Pardo J, de la Fuente JM. Dissecting the molecular mechanism of apoptosis during photothermal therapy using gold nanoprisms. ACS Nano. 2015:9(1):52-61.

7. Poon IK, Lucas CD, Rossi AG, Ravichandran KS. Apoptotic cell clearance: basic biology and therapeutic potential. Nat Rev Immunol. 2014;14(3):166-80.

8. Blachere NE, Darnell RB, Albert ML. Apoptotic cells deliver processed antigen to dendritic cells for cross-presentation. PLoS Biol. 2005;3(6):e185.

9. Schaible UE, Winau F, Sieling PA, Fischer K, Collins HL, Hagens K, Modlin RL, Brinkmann V, Kaufmann SH. Apoptosis facilitates antigen presentation to Tlymphocytes through MHC-I and CD1 in tuberculosis. Nat Med. 2003;9(8):1039-46.

10. Zheng M, Zhao P, Luo Z, Gong P, Zheng C, Zhang P, Yue C, Gao D, Ma Y, Cai L. Robust ICG theranostic nanoparticles for folate targeted cancer imaging and highly effective photothermal therapy. ACS Appl Mater Interfaces. 2014;6(9):6709-16.

11. Zheng M, Yue C, Ma Y, Gong P, Zhao P, Zheng C, Sheng Z, Zhang P, Wang Z, Cai L. Single-step assembly of DOX/ICG loaded lipid--polymer nanoparticles for highly effective chemo-photothermal combination therapy. ACS Nano. 2013;7(3):2056-67.

12. Ishizawa T, Masuda K, Urano Y, Kawaguchi Y, Satou S, Kaneko J, Hasegawa K, Shibahara J, Fukayama M, Tsuji S, et al. Mechanistic background and clinical applications of indocyanine green fluorescence imaging of hepatocellular carcinoma. Ann Surg Oncol. 2014:21(2):440-8.

13. Mordon S, Devoisselle JM, Soulie-Begu S, Desmettre T. Indocyanine green: physicochemical factors affecting its fluorescence in vivo. Microvasc Res. 1998;55(2):146-52

14. Britten CM, Singh-Jasuja H, Flamion B, Hoos A, Huber C, Kallen KJ, Khleif SN, Kreiter S, Nielsen M, Rammensee HG, et al. The regulatory landscape for actively personalized cancer immunotherapies. Nat Biotechnol. 2013;31(10):880-2.

15. Oldham RK, Dillman RO. Monoclonal antibodies in cancer therapy: 25 years of progress. J Clin Oncol. 2008;26(11):1774-7.

16. Gattinoni L, Powell DJ Jr, Rosenberg SA, Restifo NP. Adoptive immunotherapy for cancer: building on success. Nat Rev Immunol. 2006;6(5):383-93.

17. Gubin MM, Zhang X, Schuster H, Caron E, Ward JP, Noguchi T, Ivanova Y, Hundal J, Arthur CD, Krebber WJ, et al. Checkpoint blockade cancer immunotherapy targets tumour-specific mutant antigens. Nature. 2014;515(7528):577-81.

18. Geresu MA, Sultan AF, Ahmed SK, Kassa GM. Immunotherapy against cancer: a comprehensive review. J Cancer Res Exp Oncol. 2016;8(2):15-25.

19. Melero I, Gaudernack G, Gerritsen W, Huber C, Parmiani G, Scholl S, Thatcher N, Wagstaff J, Zielinski C, Faulkner l, et al. Therapeutic vaccines for cancer: an overview of clinical trials. Nat Rev Clin Oncol. 2014;11(9):509-24.

20. Wein L, Luen SJ, Savas P, Salgado R, Loi S. Checkpoint blockade in the treatment of breast cancer: current status and future directions. $\mathrm{Br} J$ Cancer. 2018;119(1):4-11.

21. Neoptolemos JP, Kleeff J, Michl P, Costello E, Greenhalf W, Palmer DH Therapeutic developments in pancreatic cancer: current and future perspectives. Nat Rev Gastroenterol Hepatol. 2018;15(6):333-48.

22. Mayes PA, Hance KW, Hoos A. The promise and challenges of immune agonist antibody development in cancer. Nat Rev Drug Discov. 2018;17(7):509-27. 
23. Chaffer $\mathrm{CL}$, Weinberg RA. A perspective on cancer cell metastasis. Science. 2011;331(6024):1559-64.

24. Yan F, Duan W, Li Y, Wu H, Zhou Y, Pan M, Liu H, Liu X, Zheng H. NIR-lasercontrolled drug release from DOX/IR-780-loaded temperature-sensitiveliposomes for chemo-Photothermal synergistic tumor therapy. Theranostics. 2016;6(13):2337-51.

25. Xu L, Kwak M, Zhang W, Lee PC, Jin JO. Time-dependent effect of E. coli LPS in spleen DC activation in vivo: alteration of numbers, expression of Costimulatory molecules, production of pro-inflammatory cytokines, and presentation of antigens. Mol Immunol. 2017;85:205-13.

26. Zhang W, Yu X, Kwak M, Xu L, Zhang L, Yu Q, Jin JO. Maturation of dendritic cells by pullulan promotes anti-cancer effect. Oncotarget. 2016;7(28):44644-59.

27. Jin JO, Han X, Yu Q. Interleukin-6 induces the generation of IL-10-producing $\operatorname{Tr} 1$ cells and suppresses autoimmune tissue inflammation. J Autoimmun. 2013;40:28-44.

28. Lopez-Noriega A, Ruiz-Hernandez E, Quinlan E, Storm G, Hennink WE, O'Brien FJ. Thermally triggered release of a pro-osteogenic peptide from a functionalized collagen-based scaffold using thermosensitive liposomes. J Control Release. 2014;187:158-66.

29. Shang N, Figini M, Shangguan J, Wang B, Sun C, Pan L, Ma Q, Zhang Z. Dendritic cells based immunotherapy. Am J Cancer Res. 2017;7(10):2091-102.

30. Cohn L, Delamarre L. Dendritic cell-targeted vaccines. Front Immunol. 2014;5:255.

31. Banchereau J, Steinman RM. Dendritic cells and the control of immunity. Nature. 1998;392(6673):245-52.

32. Xu L, Kwak M, Zhang W, Zeng L, Lee PC, Jin JO. Rehmannia glutinosa polysaccharide induces toll-like receptor 4 dependent spleen dendritic cell maturation and anti-cancer immunity. Oncoimmunology. 2017:6(7):e1325981.

33. Zhang W, Du JY, Jiang Z, Okimura T, Oda T, Yu Q, Jin JO. Ascophyllan purified from Ascophyllum nodosum induces Th1 and Tc1 immune responses by promoting dendritic cell maturation. Mar Drugs. 2014;12(7):4148-64.

34. Schnorrer P, Behrens GM, Wilson NS, Pooley JL, Smith CM, El-Sukkari D, Davey G, Kupresanin F, Li M, Maraskovsky E, et al. The dominant role of CD8+ dendritic cells in cross-presentation is not dictated by antigen capture. Proc Natl Acad Sci U S A. 2006;103(28):10729-34.

35. Melamed JR, Edelstein RS, Day ES. Elucidating the fundamental mechanisms of cell death triggered by photothermal therapy. ACS Nano. 2015;9(1):6-11.

36. Yu Z, Theoret MR, Touloukian CE, Surman DR, Garman SC, Feigenbaum L, Baxter TK, Baker BM, Restifo NP. Poor immunogenicity of a self/tumor antigen derives from peptide-MHC-I instability and is independent of tolerance. J Clin Invest. 2004;114(4):551-9.

37. Chen Q, Xu L, Liang C, Wang C, Peng R, Liu Z. Photothermal therapy with immune-adjuvant nanoparticles together with checkpoint blockade for effective cancer immunotherapy. Nat Commun. 2016;7:13193.

38. Guo L, Yan DD, Yang D, Li Y, Wang X, Zalewski O, Yan B, Lu W. Combinatorial photothermal and immuno cancer therapy using chitosancoated hollow copper sulfide nanoparticles. ACS Nano. 2014;8(6):5670-81.

39. Mellman I, Coukos G, Dranoff G. Cancer immunotherapy comes of age. Nature. 2011:480(7378):480-9.

40. Huang P, Wang X, Liang X, Yang J, Zhang C, Kong D, Wang W. Nano-, micro-, and macroscale drug delivery systems for cancer immunotherapy. Acta Biomater. 2019:85:1-26.

41. Batty CJ, Tiet P, Bachelder EM, Ainslie KM. Drug Delivery for Cancer Immunotherapy and Vaccines. Pharm Nanotechnol. 2018;6(4):232-44.

42. Wang J, Hu X, Xiang D. Nanoparticle drug delivery systems: an excellent carrier for tumor peptide vaccines. Drug Deliv. 2018;25(1):1319-27.

43. Sau S, Alsaab HO, Bhise K, Alzhrani R, Nabil G, Iyer AK. Multifunctional nanoparticles for cancer immunotherapy: a groundbreaking approach for reprogramming malfunctioned tumor environment. J Control Release. 2018:274:24-34.

44. Liu Z, Jiang W, Nam J, Moon JJ, Kim BYS. Immunomodulating nanomedicine for Cancer therapy. Nano Lett. 2018:18(11):6655-9.

\section{Publisher's Note}

Springer Nature remains neutral with regard to jurisdictional claims in published maps and institutional affiliations.

Ready to submit your research? Choose BMC and benefit from:

- fast, convenient online submission

- thorough peer review by experienced researchers in your field

- rapid publication on acceptance

- support for research data, including large and complex data types

- gold Open Access which fosters wider collaboration and increased citations

- maximum visibility for your research: over $100 \mathrm{M}$ website views per year

At BMC, research is always in progress.

Learn more biomedcentral.com/submissions 